\title{
Loss of Hearing Sensitivity in the Elderly
}

\section{Filomena Ermida da Ponte}

FFCS/ Universidade Católica Portuguesa

Corresponding Author: Filomena Ermida da Ponte, FFCS/ Universidade Católica Portuguesa.

Received date: March 23, 2021; Accepted date: April 26, 2021; Published date: May 04,2021

Citation: Filomena Ermida da Ponte., (2021) Loss of Hearing Sensitivity in the Elderly. J. Neuroscience and Neurological Surgery. 8(5); DOI:10.31579/2578-8868/172

Copyright: (c) 2021 Filomena Ermida da Ponte, This is an open-access article distributed under the terms of The Creative Commons Attribution License, which permits unrestricted use, distribution, and reproduction in any medium, provided the original author and source are credited

\section{Abstract:}

Aging, consensually assumed as a process that affects and alters significantly the cognitive and behavioral functions of the human being, encompassing multiple effects on a number of clinically significant variables, the most important being those that directly relate to the movement, ability to balance the effectiveness of mental functioning and sensory functions such as taste, smell, sight and hearing. Hearing loss in the elderly, scientifically called presbiacustia emerges quietly and is increased progressively with advancing age. This study had as its aim to contribute to the achievement of the best quality of life for elderly individuals with hearing loss (presbycusis). Thus, the objectives targeted were: trying to understand the motivations of the elderly to the use of hearing aids; determine the degree of satisfaction of users of these prostheses; evaluate how Preabycusis affects the quality of life of the elderly. The method used was qualitative oriented once interviewed the elderly users of the home. The sample was composed of 110 participants, with presbycusis, 69 female and 41 male (institutionalized seniors).

Keywords: loss of hearing; presbycusis; old age; hearing aids; quality of life

\section{Introduction}

The hearing loss associated with aging results from the sum of hearing loss resulting from physiological degeneration caused by submission to noise, ototoxic agents and lesions caused by disinfections and medical therapies. The incidence refers to approximately $60 \%$ of all people over the age of 65 .

In this study, our objective was to verify the degeneration of the auditory system over age, through supraliminal measurements and auditory sensitivity.

After the literature consulted, our theoretical options for this small study were based on an attempt to minimize the consequences of hearing loss, typically expressed in feelings of insecurity, incapacity, depression and isolation, increasing radical changes in quality of life. These problems caused by sensory deprivation of hearing can be minimized by the use of hearing aids, promoting improved communication skills. According to the literature, the prevalence of use of these prostheses by the elderly is quite low, and the first moments of acquisition are considered critical periods of adaptation, with the risk of withdrawal. Hearing loss; typically expressed in feelings of insecurity, failure, depression and Elaine, increasing radical changes in quality of life. These problems caused by sensory deprivation of the hearing can be minimized by the use of auditory compound, developed better communication skills. According to the literature, a prevalence make use of these prostheses are home to senior citizens is quite low, being the first moments of acquisition considered critical periods of adaptation, with risk of cancellation.

\section{CONCEPT}

\section{PRESBYCUSIS}

Etymologically, presbycusis of presbi (old) and acusia (hearing) means "hearing of the elderly" as well as the overall aging of the whole organism (Hungary, 2000). The hearing loss in the third age, scientifically designated by presbiacusia emerges discreetly and increases progressively with the advancement of the age. Aware of the impact of this problem, in terms of psycho-social consequences, (eg., isolation, communication difficulty, anxiety, frustration, depression) and the constraints that it entails, it is our objective, in this study, to alert to "hearing care" that is, to appeal to the quality of life of the elderly. This process of senescence places individuals in a situation of greater vulnerability to the disease, namely chronic health problems that limit their quality of life. Hearing loss; typically expressed in feelings of insecurity, failure, depression and increasing radical changes in quality of life. These problems caused by sensory deprivation of the hearing can be minimized by the use of auditory compound, developed better communication skills.

\section{Goals}

This small research aims to contribute to the achievement of the better quality of life of elderly individuals with hearing loss (presbycusis).

Thus: (i) We inquire about the motivations for the use of hearing aids;

(Ii) We verified the degree of satisfaction of the users of these prostheses;

(Iii) We identified barriers encountered in the use and maintenance of prostheses;

(Iv) We evaluated the way BP in the elderly interferes with their quality of life. 


\section{Method}

We evaluated 110 elderly, with a mean age of 75.34 years, 41 males and 69 females. The participants were submitted to an anamnesis and basic audiological evaluation.

(i) Threshold Tonal Audiometry: performed in a Model AC33 Vocal Audiometry audiometer: Speech Recognition Threshold (SRT) and Speech Recognition Percentage Index (IPRF). Acoustic Imitance Measurements: Tympanometry and Contralateral Acoustic Reflex Research Audiometry were classified according (Davis and Silverman's, 1970)

(ii) The instrument used was the technique of interview as the main way for multiple realities (Stake, 2007). Thus, we plan individual, semistructured and face-to-face interviews. Informal and in a climate that facilitates dialogue and promotes a speech that is fluent and easy to understand

After interview procedures, the elderly were submitted to basic audiological evaluation with the following procedures: Threshold Tonal Audiometry: performed in a Model AC33 Vocal Audiometry audiometer: Speech Recognition Threshold (SRT) and Speech Recognition Percentage Index (IPRF). Acoustic Imitance Measurements: Tympanometry and Contralateral Acoustic Reflex Research Audiometry were classified according to Davis and Silverman's (1970) criteria: (mild, moderate, moderate, moderately severe, severe and deep degree). For the interpretation of the results obtained, the ANOVA tests, two-proportion equality test, chi-square test and also a descriptive analysis composed of the Confidence Interval were used.

\section{DISCUSSION/RESULTS}

The results of our research suggest that most of the elderly do not adhere to the use of hearing aids. Similar to Russo (1988) we analyze the behavior and the arguments of these individuals in relation to the auditory prosthesis test. We conclude that non-adherence to this resource is due to financial problems, aesthetic reasons, (in) convenience, difficult manipulation of controls, and residual sounds. It was verified that the elderly had a need for speech-language pathology following the adaptation of the hearing aid. According to the literature, the prevalence of hearing aids among the elderly is low, and the first year after the acquisition, is considered the critical period of adaptation, within which there is a risk of withdrawal. In order to obtain better results in hearing rehabilitation, we believe that the involvement of close relatives, work associates and society as a whole, through national campaigns, is of great relevance in order to overcome prejudice, which still exists, and To reinstate the elderly in social life. Aware of the technical advances and being consensual the improvement of the quality of the prosthetics, presently prescribed, as well as the information and sensitization to its use, the adhesion is now much greater and the results quite satisfactory. In this small study, we sought to capture the essence of this theme, emphasizing the importance, as it states Peixoto, R. \& Mattos, L. (2007), of an auditory rehabilitation program to help minimize the psychosocial reactions resulting from hearing impairment in the elderly. This study revealed that the auditory alterations in the elderly population are reflected in the decrease in hearing thresholds until significant difficulties in speech comprehension, generating problems in communication and, consequently, retraction and isolation of social life. Due to these limitations inherent to hearing loss, early diagnosis is paramount in reducing the impact on the individual's social relationship with the environment.

\section{CONCLUSIONS}

With advancing age, there was a gradual increase in the degree of hearing loss. It can be concluded that, with advancing age, there was a gradual increase in the degree of hearing loss, and the audiometric configuration was descending, with greater impairment of high frequencies in the age group from 80 to 90 years, with a transversality in individuals older than 90 years. Males presented lower thresholds at $4000 \mathrm{~Hz}$ frequency compared to females. In speech intelligibility, a gradual decrease in responses was also observed with increasing age.

We conclude, therefore, that presbycusis is a decline in the status of the elderly, depriving them of communication and the promoter of isolation, associated with self-decay. The objective of this study is to emphasize prevention, encouraging periodic examination, searching for the ideal means of avoiding "hearing loss", or finding ways to promote a less invasive configuration at the level of each one, and for the benefit of all. Similar to other studies, Silva, R. \& Almeida, L. (2016),it was concluded, through the testimony of the participants, that the hearing contributed in the improvement of the quality of life of the elderly, while emphasizing the limitations presented by her.It was concluded, through the testimony of the participants, that the hearing contributed in the improvement of the quality of life of the elderly, while emphasizing the limitations presented by her.

Aware of technical progress and consensus being the improvement of the quality of dentures today prescribed, as well as information and awareness to your use, currently membership is much higher and the results are quite satisfactory.In this small study, we seek to capture the essence of that which we consider the subject of the article: psychosocial Consequences of loss of hearing sensitivity of elderly, stressing the importance, as it states Peixoto, R. \& Mattos, L. (2007) of raising awareness to the use of these prostheses and a program of auditory rehabilitation to help minimize the psychosocial reactions resulting from hearing loss in the elderly. We conclude therefore presbycusis a decline of the status of the elderly by depriving them of communication and promoter of isolation, associated to decadence.

\section{REFERENCES}

1. Boger, M.; Barreto. M.; Sampaio, A. (2016). A hearing loss in elderly and interference in language and psychosocial life. Revista Eletrónica Gestão \& Saúde. ISSN: 1982-4785

2. Menezes, C. Mário; M.; Marchori (2010). Prevalence of hearing loss and associated factors in elderly population: Londrina, Paraná

3. Silva, R.; Almeida, L. (2016) Hearing prostheses for elderly: psychosocial features, adaptation and quality of life. INTERAÇÕES, Campo Grande, MS, v. 17, n. 3, p. 463-474, jul./set. 2016

4. Peixoto, R.; Mattos, L. (2007). Audiologia do envelhecimento: Revisão da literatura e perspetivas atuais. Rev. Bras. Otorrinolaringol. vol.73 no.1 São Paulo Jan./Feb. 2007

5. Russo IP. Intervenção fonoaudiológica na terceira idade. Revinter: Rio de Janeiro; 2004

6. Russo ICP. Achados audiométricos em uma população de idosos presbiacúsicos brasileiros em função do sexo e da faixa etária. Pró fono 1993;5(1):8-10 
7. Russo, ICP (1988). Uso de próteses auditivas em idosos portadores de presbiacusia:

8. World Health Organization - WHO/OMS. "Deafness and hearing impairment". Consultado a 01 de Abril de 2012. http://www.who.int/topics/deafness/en/
9. Silman S, Silverman C A. Auditory Diagnosis. Principles and Applications. San Diego (London): Singular Publishing Group. 1997, cap 2 Audiometric Interpretation, Part VII. p. 44.
This work is licensed under Creative Commons Attribution 4.0 License

To Submit Your Article Click Here: Submit Manuscript

DOI:10.31579/2578-8868/172
Ready to submit your research? Choose Auctores and benefit from:

* fast, convenient online submission

* rigorous peer review by experienced research in your field

* rapid publication on acceptance

* authors retain copyrights

* unique DOI for all articles

* immediate, unrestricted online access

At Auctores, research is always in progress.

Learn more www.auctoresonline.org/journals/neuroscience-andneurological-surgery 